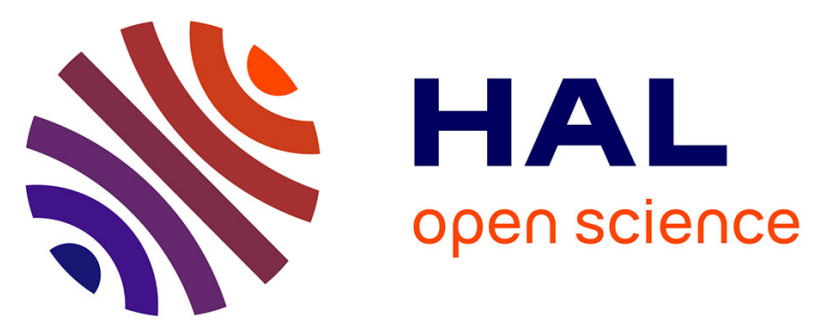

\title{
Lack of efficacy of neoadjuvant chemotherapy in adult patients with maxillo-facial high-grade osteosarcomas: A French experience in two reference centers
}

Jebrane Bouaoud, Guillaume Beinse, Nicolas Epaillard, Melika Amor-Sehlil, François Bidault, Isabelle Brocheriou, Geneviève Hervé, Jean-Philippe Spano, François Janot, Pascaline Boudou-Rouquette, et al.

\section{To cite this version:}

Jebrane Bouaoud, Guillaume Beinse, Nicolas Epaillard, Melika Amor-Sehlil, François Bidault, et al.. Lack of efficacy of neoadjuvant chemotherapy in adult patients with maxillo-facial high-grade osteosarcomas: A French experience in two reference centers. Oral Oncology, 2019, 95, pp.79 - 86. 10.1016/j.oraloncology.2019.06.011 . hal-03487032

\section{HAL Id: hal-03487032 https://hal.science/hal-03487032}

Submitted on 20 Dec 2021

HAL is a multi-disciplinary open access archive for the deposit and dissemination of scientific research documents, whether they are published or not. The documents may come from teaching and research institutions in France or abroad, or from public or private research centers.
L'archive ouverte pluridisciplinaire HAL, est destinée au dépôt et à la diffusion de documents scientifiques de niveau recherche, publiés ou non, émanant des établissements d'enseignement et de recherche français ou étrangers, des laboratoires publics ou privés.

\section{(ㄷ)(1) $\$$}

Distributed under a Creative Commons Attribution - NonCommerciall 4.0 International 


\section{TITLE PAGE}

Lack of efficacy of neoadjuvant chemotherapy in adult patients with maxillo-facial high-grade osteosarcomas: a French experience in two reference centers.

\section{Author names and affiliations:}

Jebrane Bouaoud ${ }^{a}+$, Guillaume Beinse ${ }^{b}+$, Nicolas Epaillard ${ }^{b}+$, Melika Amor-Sehlil ${ }^{c}$, François Bidault ${ }^{d}$, Isabelle Brocheriou ${ }^{e}$, Geneviève Hervé ${ }^{e}$, Jean-Philippe Spano ${ }^{b}$, François Janot ${ }^{f}$, Pascaline BoudouRouquette ${ }^{g}$, Mourad Benassarou ${ }^{a}$, Thomas Schouman ${ }^{a}$, Patrick Goudot ${ }^{a}$, Gabriel Malouf ${ }^{b} \neq$, François Goldwasser ${ }^{\mathrm{g}} \neq$, Chloe Bertolus $^{\mathrm{a}} \ddagger$

a. Department of Maxillo-facial Surgery and Stomatology, Pitié-Salpétrière Hospital, Pierre et Marie Curie University Paris 6, Sorbonne Paris Cite University, AP-HP, RESAP, Paris, 75013, France.

b. Department of Medical Oncology, Pitié-Salpétrière Hospital, Pierre et Marie Curie University Paris 6, Sorbonne Paris Cite University, AP-HP, RESAP, Paris, 75013, France.

c. Department of Radiology, Pitié-Salpétrière Hospital, Pierre et Marie Curie University Paris 6, Sorbonne Paris Cite University, AP-HP, RESAP, Paris, 75013, France.

d. Department of Radiology, Gustave Roussy Cancer Campus, 114 Rue Edouard Vaillant, Villejuif 94800, France.

e. Department of Pathology, Pitié-Salpétrière Hospital, Pierre et Marie Curie University Paris 6, Sorbonne Paris Cite University, AP-HP, Paris, 75013, France.

f. Unit of Head and Neck Surgery, Gustave Roussy Cancer Campus, 114 Rue Edouard Vaillant, Villejuif 94800, France.

g. Department of Medical Oncology, Cochin Hospital, Paris Descartes University, CARPEMParis, APHP, RESAP, Paris, 75014, France.

† These authors contributed equally to the work. ¥ These authors contributed equally to the work 


\section{Corresponding author:}

Jebrane Bouaoud, M.D

Department of Maxillo-facial Surgery and Stomatology, Pitié-Salpétrière Hospital, Pierre et Marie Curie University Paris 6, Sorbonne Paris Cite University, AP-HP, RESAP, Paris, 75013, France

E-mail_ jebrane.bouaoud@gmail.com

Phone\# $\quad+33142161049$

Word count: 2638

Conflict of interest statement: none declared

This research did not receive any specific grant from funding agencies in the public, commercial, or not-for-profit sectors. 
ABSTRACT

Introduction

Neoadjuvant chemotherapy (neo-CT) for osteosarcomas is the standard of care. Management of maxillo-facial osteosarcomas (MFOS) is challenging. In this rare disease, we collected a large cohort of patients with the aim to report the histological and radiological local response rates to neo-CT.

\section{Patients and Methods}

All consecutive adult patients treated between 2001-2016 in two French sarcoma referral centers (Pitié-Salpêtrière Hospital, APHP, RESAP France and Gustave Roussy Institute France), for a histologically proved MFOS were included. Clinical, histological and radiological data were independently reviewed. Tumor response to neo-CT was assessed clinically, radiologically with independent review using RECIST v1.1 criterion and pathologically (percentage of necrosis). Multivariate analysis was done for outcomes, tumor response and disease-free survival (DFS).

\section{Results}

A total of 35 high grade MFOS were collected. The clinical tumor response was $4 \%$ (1/24 receiving neo-CT), the radiological response was $0 \%$ (0/18 with available data) and the pathological response was $5 \%$ (1/20 with available data). Three patients (12.5\%) initially resectable became unresectable due to clinical and radiological progression during neo-CT. Tumor size and RO (clear margins) surgical resections were significantly associated with DFS.

\section{Conclusion}

MFOS is a rare disease. This large retrospective cohort of MFOS indicates the lack of benefit and potentially deleterious effects of neo-CT. We suggest privileging primary surgery in initially localized resectable MFOS. The benefit of adjuvant chemotherapy should be prospectively studied.

Key word (MeSH): head and neck cancer; osteosarcoma; neoadjuvant chemotherapy. 


\section{INTRODUCTION}

Osteosarcomas (OS) are malignant neoplasms, locally aggressive and usually affecting long extremity bones of adolescents and young adults [1,2]. Maxillo-facial OS (MFOS) are rare, representing less than ten percent of all OS [3] and typically occur in the third or fourth decade of life [4]. In this localization, metastases occur less frequently than in long bones osteosarcomas [5]. Indeed, recurrence and evolution are mainly localized to the primary site [6]. Because of its scarcity and subsequent lack of data [7], MFOS management is mostly based on long extremity OS guidelines. Multimodal management is recognized as the standard of care and has been demonstrated to improve outcomes in long extremity OS $[8,9]$. Indeed, compared to surgery alone, overall survival was increased with adjuvant multi-agent chemotherapy in long extremity OS [10].

Neoadjuvant chemotherapy (neo-CT) has been developed for the treatment of long bones OS for several reasons: (1) to choose postoperative adjuvant $\mathrm{CT}$ based on the response of the primary tumor to preoperative CT $[11,12]$ and (2) to allow more time to design endoprosthetic devices for limb-salvage procedures [13]. A good histological response to neo-CT is defined by more than $90 \%$ of necrosis on the surgical specimen. In the neoadjuvant setting, pathological response has been reported to be significantly associated with better overall survival [14], leading to establish the threshold of $>90 \%$ as a predictive marker for good overall survival. Although there is a strong correlation between the degree of necrosis and survival $[15,16]$, the criteria "good histological response to neo-CT" for extremity OS, is limited to $50 \%$ of large series in literature [17]. Moreover, considering multimodal management, neo-CT is not proven to add survival benefit $[18,19]$ and thus despite intensified treatment [20].

In MFOS, less than $30 \%$ of patients achieve good histological response after neo-CT [21]. Moreover, no significant benefit on overall survival was found in large series $[22,23]$. On the other hand, because of surgical constrains relative to maxillo-facial anatomy [24], the achievement of complete resection is a critical therapeutic parameter in this field $[4,22,25-27]$. Therefore, neo-CT appears as a potentially detrimental strategy, because of the potential lack of efficacy, as well as the delay to 
53 surgical resection. Indeed, the risk of local evolution during neo-CT, whose effectiveness is not 54 proven, is not consistent with the therapeutic challenges of MFOS.

55 In this orphan situation, the safety of neo-CT in MFOS in term of local control needs to be 56 established. Our aim is to report the histological and radiological local response rates to neo-CT in a 57 series of MFOS treated since 2001 in two MFOS referral centers in France. 


\section{PATIENTS and METHODS}

\section{Population included in the analysis}

All consecutive patients treated and followed for a MFOS between 2001 and 2016 in two referral centers in France (la Pitié-Salpêtrière Hospital, APHP, RESAP, Paris; Gustave Roussy Cancer Campus, Villejuif) were screened for inclusion in this cohort.

We included all adult patients treated for a histologically proven MFOS, with at least surgery and/or chemotherapy (with or without metastasis).

\section{Collection of data}

Collected data included: baseline patient (clinical and demographic data) and tumor characteristics (pathological and radiological data), chemotherapy regimens, surgical characteristics, outcomes (first date of relapse or progression, date of death or date of last news). Resection margins were considered as clear (R0) or not (microscopically involved (R1) or macroscopically intralesional (R2)).

All available radiological exams (CT-scan, Magnetic resonance imaging (MRI)) in each center were independently reviewed by two expert radiologists in order to collect tumor size before and after neo-CT. Radiological responses were assessed according to change in maximal tumor diameter (Recist v1.1 criterion).

Tumor histological response to neo-CT was collected from pathology reports, as Pathologists routinely evaluate it using the Rosen's criteria to assess the percent of necrotic tumor cells in the surgical specimen after neo-CT (good response if $>90 \%$ of necrosis on the surgical specimen) $[11,28]$ This study was approved by Institutional review board and done in accordance with the Helsinki declaration. Written consent was not required from patients because of the retrospective noninterventional design, consistently with French standard regulations. Collection of data and analysis was in accordance with guidelines of the French national committee for protection of personal data (CNIL). 
Objective and end points

The primary objective of this study was to describe the pathological and radiological responses to neo-CT.

Secondary outcomes of interest were disease free survival (DFS), defined by the duration between surgery and first relapse (or death) or censoring by the date of last news alive, and correlation between tumor responses and surgical margins.

\section{Statistical analyses}

The retrospective design of this study and the scarcity of the disease prevented us to calculate a population to confirm statistical hypotheses. Binary data were described by ratios. Quantitative data were described using median and range. Correlations between binary variables were assessed using Fisher exact test. Because of the limited number of patients included, correlations between binary and quantitative variables were assessed using non-parametric Wilcoxon test. Follow-up was estimated using the reverse Kaplan-Meier estimation method (1-KM). Survival curves were performed using the Kaplan-Meier method and analyzed using two-sided log-rank test. Exploratory survival analysis was performed with Cox logistic regression model. Proportional hazards assumption was tested for each analysis. Survivals are considered from the date of first treatment (surgery, or first neo-CT infusion), to the date of event of interest, censored by the date of last news. Significance was defined by $p<0.05$. All analyses were performed using R software version 3.3.3. 


\section{Patients and tumors characteristics}

105 Forty patients were screened for the inclusion (Figure 1). Thirty-five high grade MFOS were included for the final analysis ( $n=5$ excluded: other diagnosis $(n=4)$ and missing data $(n=1$; histological report unavailable).

Patient and tumor characteristics $(n=35)$ are presented in Table 1 and were consistent with literature [29]. Briefly, median age was 36.8 years old (range 18.5-84.4). All patients had good general condition, $64 \%$ were male. The delay between first symptoms and diagnosis was extremely variable, with a median time to diagnosis of 15 weeks (range 5-108). The first symptom was an evolving mass syndrome in $83 \%$ of cases (Table 1). All tumors were developed from mandibular bone $(60 \%)$, or maxillary bone (40\%). Most of tumors (75\%) had local development corresponding to stage IIA/B of AJCC staging system for long bone sarcoma. Four patients had metastasis at diagnosis (skin: $n=1$; lung: $n=3$ ) and three had radiological suspicion of lymph nodes metastasis (not confirmed histologically).

Median initial tumor size was $40 \mathrm{~mm}$ (range 15-99). All MFOS were high grade tumors. The main histological subtypes were chondroblastic $(37 \%)$, osteoblastic $(31 \%)$ or undifferentiated $(14 \%)$. Twenty-nine percent of tumors had a mixed histological type.

\section{Therapeutic management}

Twenty-four (77.4\%) patients received neo-CT. Regimens were based on Adriamycine, Platine Ifosfamide and high-dose methotrexate. Regimens heterogeneity prevented any further analyses for correlations with resection margins or survival.

Four patients ( $n=3$ localized disease and $n=1$ with lung metastasis) did not undergo surgical resection because of locally advanced/unresectable disease at initial diagnosis $(n=1)$ or after neo-CT $(n=3)$.

127 Surgical resection of tumor was performed for 31 (89\%) patients (Figure 1). Among these, 10 (32\%) 128 did not receive previous neo-CT. For the 21 patients operated after neo-CT, the median delay 
between the first cycle of neo-CT and surgery was 14 weeks (range 5-40) and 8 (38\%) had R1 resection margins. Overall, $27 / 31$ (87\%) patients had available data for surgical resection margins, 17 (63\%) were clear (R0), 10 (37\%) were marginal R1 and no intralesional R2 margins was observed. Adjuvant CT was administered to $16 / 27$ patients.

No patient received RT prior to surgery. Adjuvant RT was realized for 8 patients with positive surgical margins.

\section{Radiological response to neo-CT}

Among patients who underwent surgical resection after neo-CT $(n=21)$, responses distributions were eight $(44 \%)$ progressions (tumor size increase $>20 \%$ ), ten $(66 \%)$ stable diseases, while none had significant radiological tumor shrinkage when using RECIST1.1 criterion (decrease $>30 \%$ in tumor maximal diameter) (Figure 2). Median tumor size change from the baseline was +4 millimeters [-10; +20 ] representing a median of $+12.8 \%$ of size increase. (Table 2 ).

The three patients who received neo-CT ( $n=1$ and $n=2$ having received 6 and 4 cycles respectively) but were not resected thereafter had not radiological examinations available. They were in clinical progression. They were resectable at initial diagnosis and became unresectable after neo-CT due to the large progression of the tumor. Overall, $16 / 24$ patients $(66.7 \%)$ had an increase in tumor size or were in clinical progression during the neo-CT.

\section{Histological response to neo-CT}

Among patients who underwent surgical resection after neo-CT, 20 had histological data available.

One out of $20(5 \%)$ patient experienced a $100 \%$ tumor necrosis and was the only one responder

151 (necrosis $>90 \%$ ) to neo-CT (Figure 3). Regarding others, tumor necrosis was $\leq 30 \%$ for 14 patients 152 (70\%), 31-60\% for three patients (15\%) and 61-90\% for two patients (10\%).

\section{Survival and prognostic factors}


155 Median follow-up was 43.6 months (95\% Cl [32.1; 63.7]; range [1.0 - 160.7]). We observed 8 deaths 156 during the period of follow-up. One patient died of tumor bleeding prior to any treatment, one 157 patient treated by surgery alone died of pulmonary infection in the post-surgical period. The six 158 others had received neo-CT and died after tumor relapses either locally (3) or secondary to 159 metastatic disease progression (3).

160 Among patients who were resected for the primary tumor $(n=31 / 35), 8(26 \%)$ relapsed, with a 3161 years DFS of $76 \%$ (95\% confidence interval [60\%; 95\%]). Among the 8 patients who relapsed, 5 have 162 died at the date of last news. The 3 other patients were still alive after long follow-up (34 months, 40 163 months, 160 months)

164 R0 resections were significantly associated with a better DFS compare to R1 resections (log-rank test, $165 \mathrm{p}=0.004$ ) (Figure 4), with a 3 -years DFS of $100 \%$ versus $37.5 \%$ respectively. Other factors significantly 166 associated with poorer DFS were the median initial and pre-operative tumor sizes (Table 3).

167 Higher initial and post neo-CT tumor size were significantly associated with R1 margins 168 (supplementary table 1). 
170 This study is the first to report the radiological and pathological response rates after neo-CT for a

171 recent cohort of MFOS. During fifteen years period, 35 patients with a confirmed diagnosis of MFOS

172 were treated in two reference centers. Among this cohort of patients, 11 patients were operated

173 before any CT and 24 received neo-CT followed by surgery for 21 of them. The clinical tumor

174 response rate was $4 \%(1 / 24$ receiving neo-CT) and three patients $(12.5 \%)$ initially resectable became

175 unresectable due to clinical tumor progression ( $n=2$ maxillary and $n=1$ mandible MFOS). The

176 radiological response was 0\% (RECIST v1.1 criterion). Radiological/clinical reviews revealed that

$17766.7 \%$ of patients experienced a tumor size increase during neo-CT. The pathological response was

$1785 \%$ (1/20 with available data) and necrosis rates were $\leq 30 \%$ for $14(70 \%)$ patients. These data are

179 particularly important given that tumor size and R0 surgical resection were significantly associated 180 with DFS.

MFOS represents fewer than ten percent of all osteosarcomas and have a predominantly local development [30,31]. The scarcity of these tumors, the lack of knowledge and the heterogeneity of reported cohorts explain the lack of evidence-based treatment guidelines for the optimal management of these tumors $[32,33]$.

The benefit of neo-CT in the treatment of MFOS is not widely accepted in literature [34]. Nonsignificant or contradictory results $[22,27,35-37]$ are issues from retrospective studies that included heterogeneous patients before 2000 , with few of them receiving neo-CT [26,33]. A recent large series has reported a limited pathological response rate to neo-CT (27\%) [7].

Regarding adjuvant chemotherapy, the limited number of patients in our cohort precluded relevant not. In 2016 and 2017, Yiming Chen et al., have reported a series of n=160 head and neck osteosarcoma and affirmed that adjuvant chemotherapy improves overall survival. They found that the overall survival was significantly better with adjuvant chemotherapy among various treatment 
plans and that primary surgery alone vs. primary surgery and chemotherapy group showed borderline significance $[38,39]$.

The role of surgery, and particularly the achievement of RO resection margins, has been largely reviewed and reported to be associated with better outcomes $[4,25,26,35,40-43]$. Local failures are the main causes of death in MFOS compared to other sites [7]. The therapeutic issues and the operability of MFOS depend on tumor parameters such as size and volume $[44,45]$. It is particularly true for posterior tumors, close to the skull base. Thus, the delay until surgery and the subsequent increase in tumors size could be detrimental as suggested by the death of two patients with clinical progression during neo-CT (which were initially resectable), and by the correlation between tumor size and R1 resection. As per routine practice in our centers, some teams focused on early tumor response evaluation to discontinue neo-CT, in order to perform radical tumor resection (R0) during the window of therapeutic opportunity for surgery [46].

In line with the aforementioned therapeutic issues, our results highlight a major concern: the overall lack of efficacy of neo-CT could lead to a delay until surgery, during which tumor can grow beyond the theoretical limits of complete resection.

Why MFOS appeared so resistant to neo-CT and different from other locations remained a partially unsettled question [47]. Some large series clearly underlined biologic differences between MFOS and OS of other localization [34] reflecting the molecular heterogeneity of human osteosarcoma [48]. For example, recent molecular characterization study allowed the identification of a new-subtype of mandibular osteosarcoma with RASAL1/MDM2 amplification [49].

More generally the chemoresistance in OS appears to be mediated by numerous molecular mechanisms which include decreased intracellular drug accumulation, drug inactivation, enhanced DNA repair, perturbations in signal transduction pathways, apoptosis- and autophagy-related chemoresistance, microRNA (miRNA) dysregulation, cancer stem cell (CSC)-mediated drug resistance and Interaction of OS cells and the micro-environment [50-54] (Supplementary Table 3). 
Although identified, the precise role of each of these mechanisms of chemoresistance remains

222 unclear.

223 To illustrate it, we can mention the autophagy and apoptosis processes, which have been already

224 referred to as a double-edged sword. On one hand, they promote osteosarcoma cells survival, while in other circumstances, they can lead to tumor cell death. Furthermore, there is a close interplay between autophagy and apoptosis during OS cells development, progression and response to therapy (role of the PI3K and Akt regulators).

Furthermore, recent studies have highlighted the importance of OS-CSCs, which have been associated with chemoresistance, relapse, and metastasis events [52]. However, almost all the current studies on the mechanisms of OS-CSCS related chemoresistance are in their infancy and better understanding would help provide better targets for therapies.

232 Some studies have highlighted other biological processes which have been already reported as 233 implicated in the chemoresistance of other cancers as the epithelial-mesenchymal transition (EMT) 234 biological process (Visfatin, an EMT-related transcription factors, is involved in the cisplatin 235 resistance of osteosarcoma cells via upregulation of Snail and Zeb1 and cPLA2a, cytosolic phospholipase A2, could promote OS cell invasion) $[55,56]$. More recently Bhuvaneshwar et al., have reported intronic and intergenic hotspot regions from 26 genes significantly associated with resistance to cisplatin, doxorubicin, and methotrexate, in children with osteosarcoma [54]. Among significant results were mutations in genes belonging to AKR enzyme family (AKRD1), the cell-cell adhesion biological process (genes of the cadherin family CDH13, CDH9 and PKHD1 resulting in a phenotype called "cell adhesion-mediated drug resistance," or CAM-DR) and the PI3K pathways. Molecular studies could help to anticipate the chemoresistance. Indeed, a molecular classification of

243 OS had identified a 45-gene signature that could predict with $100 \%$ accuracy the chemoresponse of 244 osteosarcoma patients prior to the initiation of treatment [57]. This support the fact that neo-CT 245 should not be generalized but prescribed in a subset of patients with high level of expected 
chemosensitivity. This could explain why the only patient of our cohort who experienced a tumor

247 response after neo-CT had no any viable tumor cell on the surgical specimen.

248 The identification of biomarkers could allow to detect tumor onset, progression and response to

249 therapy for OS [46,58]. By predicting response to therapy, these biomarkers, as well as the immunohistochemical analysis of the microenvironment may represent novel tools for therapeutic stratification [59].

252

To identify new molecular targets and develop new drugs, further studies are required to a better understanding of the molecular pathogenesis Osteosarcoma [60]. Recent genome-wide sequencing analyzes have demonstrated that Osteosarcomas are genetically complex and heterogeneous (intraand intertumoral) [34]. Structural and numerical alterations (somatic copy number alterations) are much more common than recurrent point mutations. Regarding Cancer-causing genes, also called driver genes or drivers, numerous somatic mutations have been identified by next-generation sequencing of Osteosarcomas [61] (Supplementary Table 4). The most common driver genes associated with osteosarcomas development are TP53 and RB1. TP53 and RB1 mutations have been identified as causative driver genes in almost $50 \%$ of cases. Frequent alterations in PTEN and $\mathrm{PI3K} / \mathrm{mTOR}$ signaling pathways have also been reported. Furthermore, about $90 \%$ of all osteosarcomas appear to have mutations in BRCA-associated genes and genomically show a striking similarity to BRCA1 / 2-mutated tumors (so-called 'BRCAness')[34,61]. It suggests that a high percentage of OS tumors may be HRR-deficient (homologous recombination repair defect) and therefore be vulnerable to additional DNA damage caused by double- strand breaks.

At all, like a double-edged sword, all these alterations confer a growth advantage, but also creates vulnerabilities in osteosarcoma cells. This give us opportunities to test targeted therapies targeting 269 the different genes and pathways involved [62,63] (Supplementary table 5).

270 Some recent studies support for the potential uses of immunotherapy, including monoclonal 271 antibodies, immunomodulators, Adoptive T-cell therapy, vaccine therapy, Immunologic checkpoint 
$2736)$.

274 At all, combination strategies are probably necessary to achieve meaningful and durable responses

275 to therapies for osteosarcoma, especially immunotherapies. Indeed, as seen with conventional CT,

276 tumors development involves multiple pathways to resist to therapies. The recent development

277 developments in genomics, therapeutics and imaging technologies will allow the early detection of

278 the genomic risk of sarcomas for each patient and may participate to better personalized

279 management.

280

Despite the inherent limitations due to our retrospective data collection, and the relatively limited number of patients analyzed, which precluded further analysis of overall survival, our results were consistent with other series [34]. Indeed, our results suggest that MFOS should not be managed as OS of other localization. The natural history of MFOS is distinctive from other sites [65]. Regarding demographic pattern, the mean age of diagnosis of MFOS is 30 years of age while children and adolescents are most often affected for other sites [38]. Regarding embryologic development, head and neck bones are structurally quite different in origin from the body. Furthermore, when compared to long bones OS, MFOS showed no clinical, radiological and histological chemosensitivity [66]. Finally, this disease seems to harbor a different evolution, characterized by a local invasion more than lung metastasis, which suggest the need to a better local control rather than to eradicate micrometastasis. 


\section{Conclusion}

293 MFOS is a rare disease. This large retrospective cohort of MFOS indicates the lack of benefit and

294 potentially deleterious effects of neo-CT. We suggest privileging primary surgery in initially localized

295 resectable MFOS. The benefit of adjuvant chemotherapy should be prospectively studied.

296 Neo-CT could benefit only for a limited group of patients with high predisposition of

297 chemosensitivity, on the basis of molecular analysis. Collaborative and large high-throughput

298 genomic analysis are warranted to better characterize MFOS, and to allow the emergence of

299 predictive biomarkers, as well as the development of targeted therapies. 
301 [1] Luetke A, Meyers PA, Lewis I, Juergens H. Osteosarcoma treatment - where do we stand? A state of the art review. Cancer Treat Rev 2014;40:523-32. doi:10.1016/j.ctrv.2013.11.006.

[2] Bielack SS, Hecker-Nolting S, Blattmann C, Kager L. Advances in the management of osteosarcoma. F1000Research 2016;5. doi:10.12688/f1000research.9465.1.

[3] Guadagnolo BA, Zagars GK, Raymond AK, Benjamin RS, Sturgis EM. Osteosarcoma of the jaw/craniofacial region: outcomes after multimodality treatment. Cancer 2009;115:3262-70. doi:10.1002/cncr.24297.

[4] Jasnau S, Meyer U, Potratz J, Jundt G, Kevric M, Joos UK, et al. Craniofacial osteosarcoma Experience of the cooperative German-Austrian-Swiss osteosarcoma study group. Oral Oncol 2008;44:286-94. doi:10.1016/j.oraloncology.2007.03.001.

[5] Laskar S, Basu A, Muckaden MA, D'Cruz A, Pai S, Jambhekar N, et al. Osteosarcoma of the head and neck region: lessons learned from a single-institution experience of 50 patients. Head Neck 2008;30:1020-6. doi:10.1002/hed.20820.

[6] Ketabchi A, Kalavrezos N, Newman L. Sarcomas of the head and neck: a 10-year retrospective of 25 patients to evaluate treatment modalities, function and survival. Br J Oral Maxillofac Surg 2011;49:116-20. doi:10.1016/j.bjoms.2010.02.012.

[7] Thariat J, Julieron M, Brouchet A, Italiano A, Schouman T, Marcy P-Y, et al. Osteosarcomas of the mandible: are they different from other tumor sites? Crit Rev Oncol Hematol 2012;82:280-95. doi:10.1016/j.critrevonc.2011.07.001.

[8] Durfee RA, Mohammed M, Luu HH. Review of Osteosarcoma and Current Management. Rheumatol Ther 2016;3:221-43. doi:10.1007/s40744-016-0046-y.

[9] Whelan JS, Jinks RC, McTiernan A, Sydes MR, Hook JM, Trani L, et al. Survival from highgrade localised extremity osteosarcoma: combined results and prognostic factors from three European Osteosarcoma Intergroup randomised controlled trials. Ann Oncol Off J Eur Soc Med Oncol 2012;23:1607-16. doi:10.1093/annonc/mdr491.

[10] The ESMO. Bone sarcomas: ESMO Clinical Practice Guidelines for diagnosis, treatment and follow-up. Ann Oncol 2014;25:iii113-23. doi:10.1093/annonc/mdu256.

[11] Rosen G, Caparros B, Huvos AG, Kosloff C, Nirenberg A, Cacavio A, et al. Preoperative chemotherapy for osteogenic sarcoma: selection of postoperative adjuvant chemotherapy based on the response of the primary tumor to preoperative chemotherapy. Cancer 1982;49:1221-30.

[12] Link MP, Goorin AM, Miser AW, Green AA, Pratt CB, Belasco JB, et al. The effect of adjuvant chemotherapy on relapse-free survival in patients with osteosarcoma of the extremity. N Engl J Med 1986;314:1600-6. doi:10.1056/NEJM198606193142502.

[13] Isakoff MS, Bielack SS, Meltzer P, Gorlick R. Osteosarcoma: Current Treatment and a Collaborative Pathway to Success. J Clin Oncol Off J Am Soc Clin Oncol 2015;33:3029-35. doi:10.1200/JCO.2014.59.4895.

[14] Marina N, Gebhardt M, Teot L, Gorlick R. Biology and therapeutic advances for pediatric 
osteosarcoma. The Oncologist 2004;9:422-41.

[15] Provisor AJ, Ettinger LJ, Nachman JB, Krailo MD, Makley JT, Yunis EJ, et al. Treatment of nonmetastatic osteosarcoma of the extremity with preoperative and postoperative chemotherapy: a report from the Children's Cancer Group. J Clin Oncol Off J Am Soc Clin Oncol 1997;15:76-84. doi:10.1200/JCO.1997.15.1.76.

[16] Bacci G, Longhi A, Ferrari S, Briccoli A, Donati D, De Paolis M, et al. Prognostic significance of serum lactate dehydrogenase in osteosarcoma of the extremity: experience at Rizzoli on 1421 patients treated over the last 30 years. Tumori 2004;90:478-84.

[17] Friebele JC, Peck J, Pan X, Abdel-Rasoul M, Mayerson JL. Osteosarcoma: A Meta-Analysis and Review of the Literature. Am J Orthop Belle Mead NJ 2015;44:547-53.

[18] Gerrand C, Athanasou N, Brennan B, Grimer R, Judson I, Morland B, et al. UK guidelines for the management of bone sarcomas. Clin Sarcoma Res 2016;6. doi:10.1186/s13569-016-0047-1.

[19] Mirabello L, Troisi RJ, Savage SA. Osteosarcoma incidence and survival rates from 1973 to 2004: Data from the Surveillance, Epidemiology, and End Results Program. Cancer 2009;115:153143. doi:10.1002/cncr.24121.

[20] Meyers PA, Gorlick R, Heller G, Casper E, Lane J, Huvos AG, et al. Intensification of preoperative chemotherapy for osteogenic sarcoma: results of the Memorial Sloan-Kettering (T12) protocol. J Clin Oncol Off J Am Soc Clin Oncol 1998;16:2452-8. doi:10.1200/JCO.1998.16.7.2452.

[21] Boon E, van der Graaf WTA, Gelderblom H, Tesselaar MET, van Es RJJ, Oosting SF, et al. Impact of chemotherapy on the outcome of osteosarcoma of the head and neck in adults. Head Neck 2017;39:140-6. doi:10.1002/hed.24556.

[22] Thariat J, Schouman T, Brouchet A, Sarini J, Miller RC, Reychler H, et al. Osteosarcomas of the mandible: multidisciplinary management of a rare tumor of the young adult a cooperative study of the GSF-GETO, Rare Cancer Network, GETTEC/REFCOR and SFCE. Ann Oncol Off J Eur Soc Med Oncol 2013;24:824-31. doi:10.1093/annonc/mds507.

[23] Canadian Society of Otolaryngology-Head and Neck Surgery Oncology Study Group. Osteogenic sarcoma of the mandible and maxilla: a Canadian review (1980-2000). J Otolaryngol 2004;33:139-44.

[24] Nthumba PM. Osteosarcoma of the jaws: a review of literature and a case report on synchronous multicentric osteosarcomas. World J Surg Oncol 2012;10:240. doi:10.1186/1477-7819$10-240$.

[25] Laskar S, Basu A, Muckaden MA, D’Cruz A, Pai S, Jambhekar N, et al. Osteosarcoma of the head and neck region: lessons learned from a single-institution experience of 50 patients. Head Neck 2008;30:1020-6. doi:10.1002/hed.20820.

[26] Granados-Garcia M, Luna-Ortiz K, Castillo-Oliva HA, Villavicencio-Valencia V, HerreraGómez A, Mosqueda-Taylor A, et al. Free osseous and soft tissue surgical margins as prognostic factors in mandibular osteosarcoma. Oral Oncol 2006;42:172-6. doi:10.1016/j.oraloncology.2005.06.027.

[27] Patel SG, Meyers P, Huvos AG, Wolden S, Singh B, Shaha AR, et al. Improved outcomes in 
patients with osteogenic sarcoma of the head and neck. Cancer 2002;95:1495-503. doi:10.1002/cncr.10849.

[28] Huvos AG, Rosen G, Marcove RC. Primary osteogenic sarcoma: pathologic aspects in 20 patients after treatment with chemotherapy en bloc resection, and prosthetic bone replacement. Arch Pathol Lab Med 1977;101:14-8.

[29] van den Berg H, Schreuder WH, de Lange J. Osteosarcoma: A Comparison of Jaw versus Nonjaw Localizations and Review of the Literature. Sarcoma 2013;2013. doi:10.1155/2013/316123.

[30] O’Neill JP, Bilsky MH, Kraus D. Head and neck sarcomas: epidemiology, pathology, and management. Neurosurg Clin N Am 2013;24:67-78. doi:10.1016/j.nec.2012.08.010.

[31] Sarkar R. Pathological and clinical features of primary osseous tumours of the jaw. J Bone Oncol 2014;3:90-5. doi:10.1016/j.jbo.2014.06.001.

[32] Tudor-Green B, Fonseca FP, Gomez RS, Brennan PA. Current update on the diagnosis and management of head and neck hard tissue sarcomas. J Oral Pathol Med Off Publ Int Assoc Oral Pathol Am Acad Oral Pathol 2017;46:667-73. doi:10.1111/jop.12573.

[33] Thiele OC, Freier K, Bacon C, Egerer G, Hofele CM. Interdisciplinary combined treatment of craniofacial osteosarcoma with neoadjuvant and adjuvant chemotherapy and excision of the tumour: a retrospective study. Br J Oral Maxillofac Surg 2008;46:533-6. doi:10.1016/j.bjoms.2008.03.010.

[34] Baumhoer D, Brunner P, Eppenberger-Castori S, Smida J, Nathrath M, Jundt G.

Osteosarcomas of the jaws differ from their peripheral counterparts and require a distinct treatment approach. Experiences from the DOESAK Registry. Oral Oncol 2014;50:147-53. doi:10.1016/j.oraloncology.2013.10.017.

[35] Kassir RR, Rassekh CH, Kinsella JB, Segas J, Carrau RL, Hokanson JA. Osteosarcoma of the head and neck: meta-analysis of nonrandomized studies. The Laryngoscope 1997;107:56-61.

[36] Granowski-LeCornu M, Chuang S-K, Kaban LB, August M. Osteosarcoma of the jaws: factors influencing prognosis. J Oral Maxillofac Surg Off J Am Assoc Oral Maxillofac Surg 2011;69:2368-75. doi:10.1016/j.joms.2010.10.023.

[37] Mücke T, Mitchell DA, Tannapfel A, Wolff K-D, Loeffelbein DJ, Kanatas A. Effect of neoadjuvant treatment in the management of osteosarcomas of the head and neck. J Cancer Res Clin Oncol 2014;140:127-31. doi:10.1007/s00432-013-1550-x.

[38] Chen Y, Shen Q, Gokavarapu S, Lin C, Yahiya null, Cao W, et al. Osteosarcoma of head and neck: A retrospective study on prognostic factors from a single institute database. Oral Oncol 2016;58:1-7. doi:10.1016/j.oraloncology.2016.04.008.

[39] Chen Y, Gokavarapu S, Shen Q, Liu F, Cao W, Ling Y, et al. Chemotherapy in head and neck osteosarcoma: Adjuvant chemotherapy improves overall survival. Oral Oncol 2017;73:124-31. doi:10.1016/j.oraloncology.2017.08.017.

[40] Mücke T, Mitchell DA, Tannapfel A, Hölzle F, Kesting MR, Wolff K-D, et al. Outcome in adult patients with head and neck sarcomas--a 10-year analysis. J Surg Oncol 2010;102:170-4. doi: $10.1002 /$ jso.21595. 
[41] Kämmerer PW, Shabazfar N, Vorkhshori Makoie N, Moergel M, Al-Nawas B. Clinical, therapeutic and prognostic features of osteosarcoma of the jaws - experience of 36 cases. J CranioMaxillo-Fac Surg Off Publ Eur Assoc Cranio-Maxillo-Fac Surg 2012;40:541-8. doi:10.1016/j.jcms.2011.10.001.

[42] Chen YM, Shen QC, Gokavarapu S, Ong HS, Cao W, Ji T. Osteosarcoma of the Mandible: A Site-Specific Study on Survival and Prognostic Factors. J Craniofac Surg 2016;27:1929-33. doi:10.1097/SCS.0000000000002968.

[43] Jeong H-I, Lee MJ, Nam W, Cha I-H, Kim HJ. Osteosarcoma of the jaws in Koreans: analysis of 26 cases. J Korean Assoc Oral Maxillofac Surg 2017;43:312-7. doi:10.5125/jkaoms.2017.43.5.312.

[44] Lee RJ, Arshi A, Schwartz HC, Christensen RE. Characteristics and prognostic factors of osteosarcoma of the jaws: a retrospective cohort study. JAMA Otolaryngol-- Head Neck Surg 2015;141:470-7. doi:10.1001/jamaoto.2015.0340.

[45] Gadwal SR, Gannon FH, Fanburg-Smith JC, Becoskie EM, Thompson LD. Primary osteosarcoma of the head and neck in pediatric patients: a clinicopathologic study of 22 cases with a review of the literature. Cancer 2001;91:598-605.

[46] Kimura Y, Tomihara K, Tachinami H, Imaue S, Nakamori K, Fujiwara K, et al. Conventional osteosarcoma of the mandible successfully treated with radical surgery and adjuvant chemotherapy after responding poorly to neoadjuvant chemotherapy: a case report. J Med Case Reports 2017;11. doi:10.1186/s13256-017-1386-0.

[47] Ferrari D, Moneghini L, Allevi F, Biglioli GB and F. Osteosarcoma of the Jaw: Classification, Diagnosis and Treatment 2017. doi:10.5772/67564.

[48] Penel N, Coindre J-M, Giraud A, Terrier P, Ranchere-Vince D, Collin F, et al. Presentation and outcome of frequent and rare sarcoma histologic subtypes: A study of 10,262 patients with localized visceral/soft tissue sarcoma managed in reference centers. Cancer 2017. doi:10.1002/cncr.31176.

[49] Guérin M, Thariat J, Ouali M, Bouvier C, Decouvelaere A-V, Cassagnau E, et al. A new subtype of high-grade mandibular osteosarcoma with RASAL1/MDM2 amplification. Hum Pathol 2016;50:70-8. doi:10.1016/j.humpath.2015.11.012.

[50] HE H, NI J, HUANG J. Molecular mechanisms of chemoresistance in osteosarcoma (Review). Oncol Lett 2014;7:1352-62. doi:10.3892/ol.2014.1935.

[51] Li J, Yang Z, Li Y, Xia J, Li D, Li H, et al. Cell apoptosis, autophagy and necroptosis in osteosarcoma treatment. Oncotarget 2016;7:44763-78. doi:10.18632/oncotarget.8206.

[52] Abarrategi A, Tornin J, Martinez-Cruzado L, Hamilton A, Martinez-Campos E, Rodrigo JP, et al. Osteosarcoma: Cells-of-Origin, Cancer Stem Cells, and Targeted Therapies. Stem Cells Int 2016;2016. doi:10.1155/2016/3631764.

[53] Lindsey BA, Markel JE, Kleinerman ES. Osteosarcoma Overview. Rheumatol Ther 2016;4:25-43. doi:10.1007/s40744-016-0050-2.

[54] Bhuvaneshwar K, Harris M, Gusev Y, Madhavan S, Iyer R, Vilboux T, et al. Genome sequencing analysis of blood cells identifies germline haplotypes strongly associated with drug 
resistance in osteosarcoma patients. BMC Cancer 2019;19. doi:10.1186/s12885-019-5474-y.

[55] Wang D, Qian G, Wang J, Wang T, Zhang L, Yang P, et al. Visfatin is involved in the cisplatin resistance of osteosarcoma cells via upregulation of Snail and Zeb1. Cancer Biol Ther 2019:1-8. doi:10.1080/15384047.2019.1591675.

[56] Pang X, Yin P, Han J, Wang Z, Zheng F, Chen X. cPLA2a correlates with metastasis and poor prognosis of osteosarcoma by facilitating epithelial-mesenchymal transition. Pathol Res Pract 2019. doi:10.1016/j.prp.2019.03.026.

[57] Lau CC. Molecular classification of osteosarcoma. Cancer Treat Res 2009;152:459-65. doi:10.1007/978-1-4419-0284-9_26.

[58] Raimondi L, De Luca A, Costa V, Amodio N, Carina V, Bellavia D, et al. Circulating biomarkers in osteosarcoma: new translational tools for diagnosis and treatment. Oncotarget 2017;8:100831-51. doi:10.18632/oncotarget.19852.

[59] Gomez-Brouchet A, Illac C, Gilhodes J, Bouvier C, Aubert S, Guinebretiere J-M, et al. CD163-positive tumor-associated macrophages and CD8-positive cytotoxic lymphocytes are powerful diagnostic markers for the therapeutic stratification of osteosarcoma patients: An immunohistochemical analysis of the biopsies fromthe French OS2006 phase 3 trial. Oncoimmunology 2017;6:e1331193. doi:10.1080/2162402X.2017.1331193.

[60] Chiappetta C, Mancini M, Lessi F, Aretini P, De Gregorio V, Puggioni C, et al. Whole-exome analysis in osteosarcoma to identify a personalized therapy. Oncotarget 2017;8:80416-28. doi:10.18632/oncotarget.19010.

[61] Rickel K, Fang F, Tao J. Molecular genetics of osteosarcoma. Bone 2017;102:69-79. doi:10.1016/j.bone.2016.10.017.

[62] Brown HK, Schiavone K, Gouin F, Heymann M-F, Heymann D. Biology of Bone Sarcomas and New Therapeutic Developments. Calcif Tissue Int 2018;102:174-95. doi:10.1007/s00223-0170372-2.

[63] Wedekind MF, Wagner LM, Cripe TP. Immunotherapy for osteosarcoma: Where do we go from here? Pediatr Blood Cancer 2018;65:e27227. doi:10.1002/pbc.27227.

[64] WAN J, ZHANG X, LIU T, ZHANG X. Strategies and developments of immunotherapies in osteosarcoma. Oncol Lett 2016;11:511-20. doi:10.3892/ol.2015.3962.

[65] Peng KA, Grogan T, Wang MB. Head and neck sarcomas: analysis of the SEER database. Otolaryngol--Head Neck Surg Off J Am Acad Otolaryngol-Head Neck Surg 2014;151:627-33. doi:10.1177/0194599814545747.

[66] Bacci G, Longhi A, Versari M, Mercuri M, Briccoli A, Picci P. Prognostic factors for osteosarcoma of the extremity treated with neoadjuvant chemotherapy: 15-year experience in 789 patients treated at a single institution. Cancer 2006;106:1154-61. doi:10.1002/cncr.21724. 
Figure legends and tables.

Figure 1. Flow-chart: patient selection and treatments.

Table 1. Patients' baseline characteristics and initial therapeutic management $(n=35)$.

Figure 2. Radiological response to neoadjuvant chemotherapy for patients who underwent surgery.

Patients included: $n=18$. (data missing for 3 patients; Bars represent the percentage tumor size change relative to baseline; Bars in black or with \# highlight patients with uncomplete resection);

Figure 3. Histological response to neoadjuvant chemotherapy for the $n=18$ patients who underwent surgery with available data.

Table 2. Radiological and pathological response to neoadjuvant chemotherapy.

Figure 4. Disease free survival according to surgical margins

Patients included: $n=31$ ( $n=4$ NA, $n=17$ complete resection R0, n=20 incomplete resection either R1 or R2).

Table 3. Disease free survival following surgical resection according to patients' characteristics.

Patients included: $\mathrm{n}=31$ (in 21 patients who underwent chemotherapy - as assessed by radiological reviewing. Maximal diameter was taken into account. Pathological response as assessed by tumor necrosis on surgical specimen).

Supplementary Table 1. Patients' characteristics associated with positive surgical resection margins $(n=27)$.

Supplementary table 2. Differences between treatments of patients with MFOS according to their metastatic status. (MFOS: maxillofacial osteosarcoma; (M-) patients with localized/non-metastatic MFOS and $(\mathrm{M}+)$ with metastases; CT: chemotherapy; NA: Not applicable).

Supplementary table 3. Molecular mechanisms of chemoresistance in OS (adapted from He et al., 2014, Li et al., 2016, Abarrategi et al., 2016 and Lindsey et al., 2016)

Supplementary table 4. Validated somatic mutations in candidate cancer genes identified by nextgeneration sequencing for Osteosarcoma. Specifically, Tumor Suppressor genes including p53, Rb, 
RECQL4, BLM, and WRN play a critical role in the development of osteosarcoma in patients with inherited familial syndromes that predisposed to this condition: Li-Fraumeni, hereditary retinoblastoma, Rothmund-Thomson, Bloom or Werner syndromes, respectively (adapted from Baumhoer 2018 and Rickel et al., 2017).

Supplementary table 5. Recent clinical trials for targeted therapies, immunotherapies and immunomodulators. (more details, see: https://clinicaltrials.gov/ct2/search/advanced/osteosarcoma; adapted from Wan et al., 2016 and Wedekind et al., 2018)

Supplementary table 6. Different type of targeted therapies using Monoclonal antibodies (mab) and immunotherapies for osteosarcoma treatment. (For more details, see: Wan et al., 2016, Wedekind et al., 2018) 


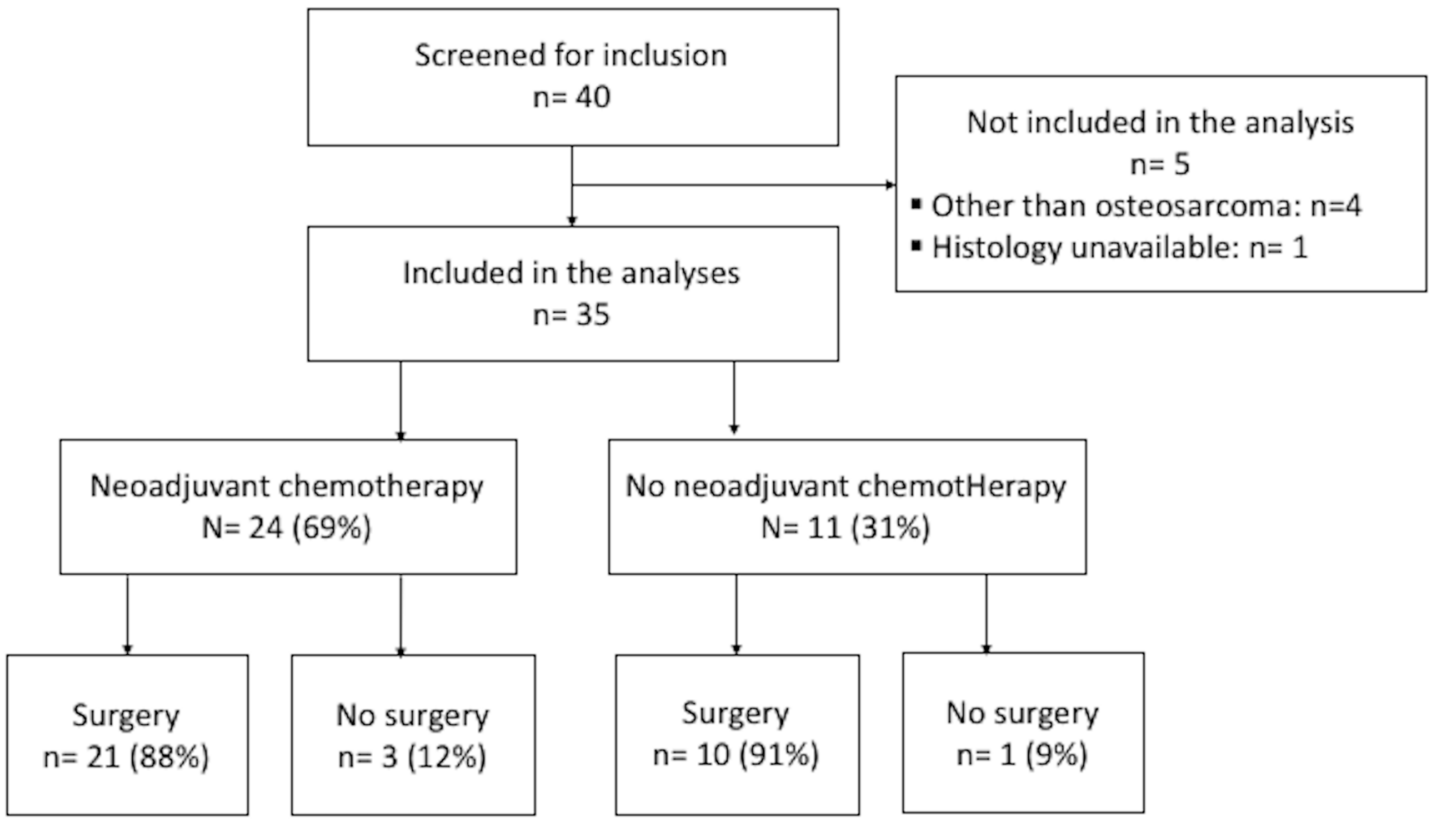


$80.0 \%$

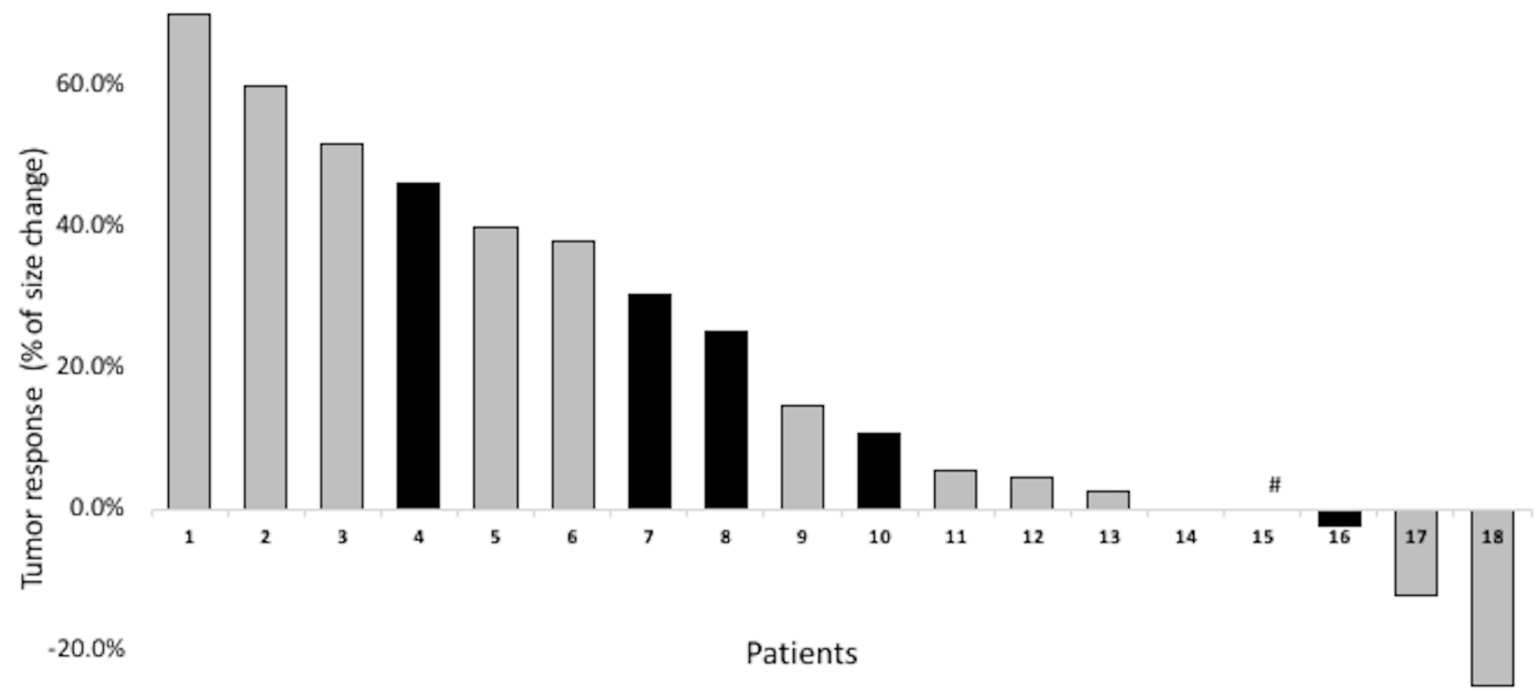




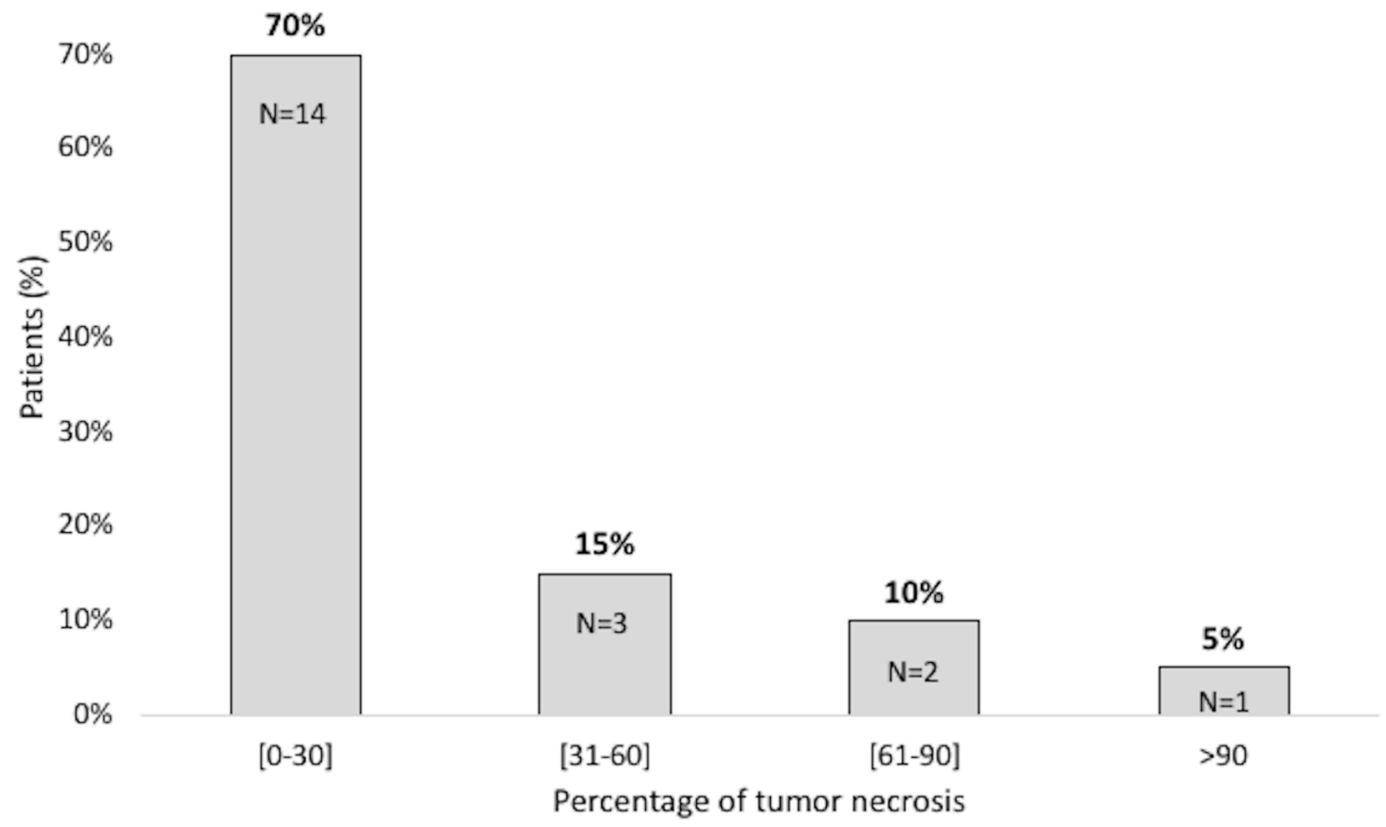




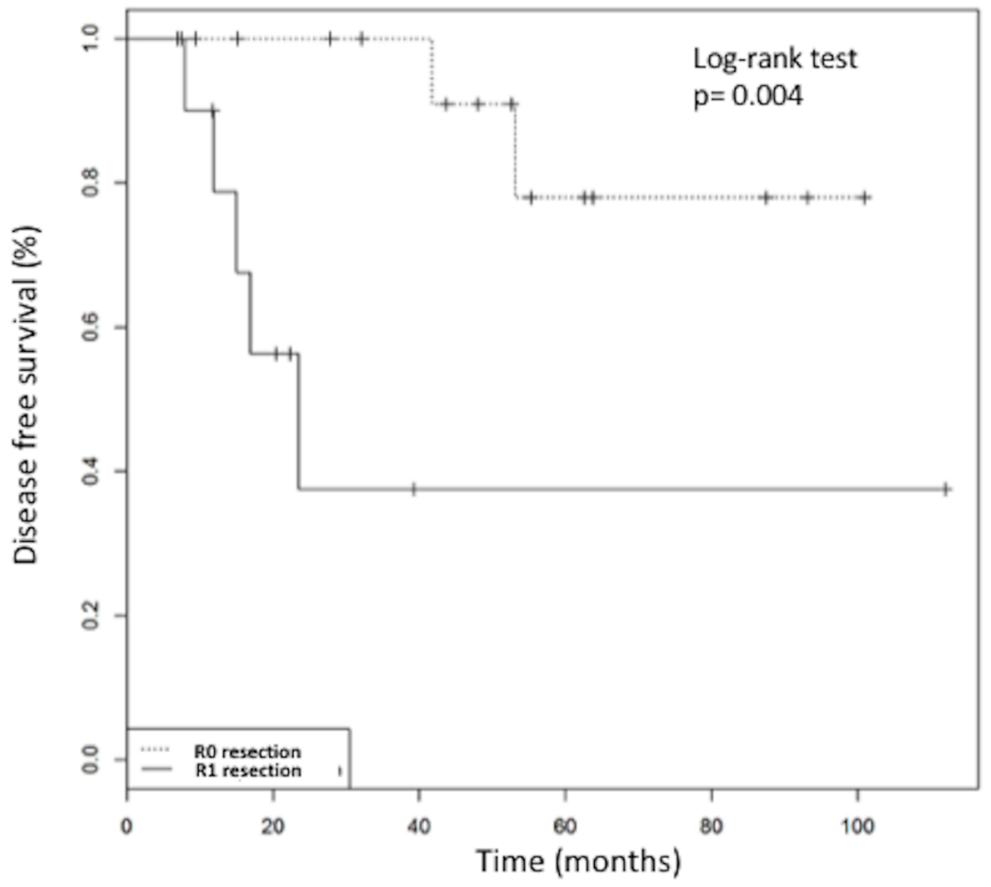


Table 1

Table 1. Patients' baseline characteristics and initial therapeutic management $(n=35)$

\begin{tabular}{|c|c|c|}
\hline \multirow{2}{*}{$\begin{array}{l}\text { Variables } \\
\text { Age (Median, range) }\end{array}$} & \multicolumn{2}{|c|}{ Overall population } \\
\hline & 36.8 & $18.5-84.4$ \\
\hline \multicolumn{3}{|l|}{ Gender $(N, \%)$} \\
\hline Male & 23 & $64 \%$ \\
\hline Female & 12 & $36 \%$ \\
\hline \multicolumn{3}{|l|}{ ECOG-PS at diagnostic (N, \%) } \\
\hline 0 & 33 & $94 \%$ \\
\hline 1 & 1 & $3 \%$ \\
\hline Missing data & 1 & $3 \%$ \\
\hline \multicolumn{3}{|l|}{ Histological (N, \%) } \\
\hline Osteoblastic & 11 & $31 \%$ \\
\hline Chondroblastic & 13 & $37 \%$ \\
\hline Fibroblastic & 1 & $3 \%$ \\
\hline Undifferentiated & 5 & $14 \%$ \\
\hline Not specified & 5 & $30 \%$ \\
\hline Mixed histology & 10 & $29 \%$ \\
\hline \multicolumn{3}{|l|}{ Primary tumor site $(\mathrm{N}, \%)$} \\
\hline Maxillary bone & 14 & $40 \%$ \\
\hline Mandibular bone & 21 & $60 \%$ \\
\hline \multicolumn{3}{|l|}{ First symptom (N, \%) } \\
\hline Evolving mass syndrome & 29 & $83 \%$ \\
\hline Pain & 6 & $17 \%$ \\
\hline \multicolumn{3}{|l|}{ AJCC stages $(\mathrm{N}, \%)$} \\
\hline IIA & 24 & $69 \%$ \\
\hline IIB & 2 & $6 \%$ \\
\hline IVA & 4 & $11 \%$ \\
\hline IVB & 3 & $9 \%$ \\
\hline Missing data (n) & 2 & \\
\hline Tumor size $^{\mathrm{a}}$ (mm: median, range) & 40 & $15.0-99.0$ \\
\hline Missing data & 4 & \\
\hline Neoadjuvant chemotherapy $(\mathrm{N}, \%)$ & 24 & $69 \%$ \\
\hline Carcinologic resection ( $\mathrm{N}, \%)$ & 31 & $89 \%$ \\
\hline Total $(\mathrm{N}, \%)$ & 35 & $100 \%$ \\
\hline
\end{tabular}

AJCC: American Joint Committee on Cancer classification for osteosarcoma ${ }^{a}$ tumor size according to the largest dimension; mm: millimeter; 
Table 2

Table 2. Radiological and pathological response to neoadjuvant chemotherapy.

\begin{tabular}{|c|c|c|}
\hline & \multicolumn{2}{|c|}{ Overall population $(n=24)$} \\
\hline $\begin{array}{l}\text { Median change in tumor size (in millimeters) from baseline }{ }^{a} \\
\text { (median [range]; \% of size progression) }\end{array}$ & $+4[-10 ;+20]$ & $+12.8 \%$ \\
\hline Objective response $^{\mathrm{a}}(\mathrm{N}, \%)$ & & \\
\hline Partial response ${ }^{\mathrm{b}}$ & 0 & $0 \%$ \\
\hline Stable disease & 10 & $66 \%$ \\
\hline Progressive disease & 8 & $44 \%$ \\
\hline Pathological response $^{\mathrm{c}}>\mathbf{9 0 \%}(\mathrm{N}, \%)$ & 1 & $5 \%$ \\
\hline
\end{tabular}

mm: millimeter;

${ }^{a}$ Among 21 patients who underwent chemotherapy - as assessed by radiological reviewing.

${ }^{b}$ Decreasing in tumor largest dimension $>30 \%$.

${ }^{\mathrm{c}}$ Pathological response as assessed by tumor necrosis on surgical specimen. 
Table 3

Table 3. Disease free survival following surgical resection according to patients' characteristics

\begin{tabular}{|c|c|c|c|c|}
\hline Variables & Recurrence (\%) & 3-years DFS [95\%Cl] & $\mathrm{HR}[95 \% \mathrm{Cl}]^{\mathrm{a}}$ & $p$-value ${ }^{a}$ \\
\hline $\begin{array}{l}\text { Age (year) } \\
>\text { median } \\
<\text { median }\end{array}$ & $\begin{array}{l}3 / 16(18.8 \%) \\
5 / 15(33.3 \%)\end{array}$ & $\begin{array}{l}93 \%[80 \% ; 100 \%] \\
52 \%[29 \% ; 97 \%]\end{array}$ & $3.45[0.79 ; 15.10]$ & 0.1 \\
\hline $\begin{array}{l}\text { Primary tumor site } \\
\text { Mandibular bone } \\
\text { Maxillary bone }\end{array}$ & $\begin{array}{l}3 / 19(15.8 \%) \\
5 / 12(41.7 \%)\end{array}$ & $\begin{array}{l}84 \%[66 \% ; 100 \%] \\
67 \%[45 \% ; 99 \%]\end{array}$ & $\begin{array}{l}0.47[0.11 ; 1.99] \\
-\end{array}$ & 0.308 \\
\hline Median initial tumor size $(\mathrm{mm})^{\mathrm{bc}}$ & $7 / 27(25.9 \%)$ & - & $1.05[1.01 ; 1.10]$ & 0.026 \\
\hline $\begin{array}{l}\text { Median tumor size before surgery } \\
\text { (including patients treated with } \\
\text { neoCT) }(\mathrm{mm})^{c}\end{array}$ & $7 / 26(26.9 \%)$ & - & $1.04[1.00 ; 1.08]$ & 0.031 \\
\hline $\begin{array}{l}\text { Neo adjuvant chemotherapy } \\
\text { Yes } \\
\text { No }\end{array}$ & $\begin{array}{l}5 / 21(23.8 \%) \\
3 / 10(30 \%)\end{array}$ & $\begin{array}{l}79 \%[62 \% ; 100 \%] \\
67 \%[36 \% ; 100 \%]\end{array}$ & $\begin{array}{l}0.56[0.13 ; 2.38] \\
-\end{array}$ & 0.438 \\
\hline $\begin{array}{l}\text { Surgical resection } \\
\text { R0 } \\
\text { R1 }\end{array}$ & $\begin{array}{l}2 / 17(11.8 \%) \\
5 / 10(50 \%)\end{array}$ & $\begin{array}{l}100 \%[100 \% ; 100 \%] \\
38 \%[14 \% ; 100 \%]\end{array}$ & $8.96[1.58 ; 50.68]$ & 0.004 \\
\hline
\end{tabular}

DFS: Disease free survival.

HR: hazard ratio.

95\% Cl: $95 \%$ confidence interval.

$\mathrm{mm}$ : millimeter.

a estimated using Cox regression model.

b assessed by radiological reviewing. largest dimension was taken into account.

${ }^{c}$ these variables were considered as continuous variables 